\title{
Lei de Responsabilidade Fiscal: efeitos e consequências sobre os municípios alagoanos no período 2000-10
}

\author{
Anderson Henrique dos Santos Araújo \\ Universidade Federal de Alagoas (Ufal) / Campus do Sertão - sede \\ Maceió / AL - Brasil \\ José Emilio dos Santos Filho \\ Universidade Federal de Alagoas (Ufal) / Pró-reitoria de Gestão Institucional (Proginst) \\ Maceió / AL - Brasil \\ Fábio Guedes Gomes \\ Universidade Federal de Alagoas (Ufal) / Faculdade de Economia, Administração e \\ Contabilidade (Feac) \\ Maceió / AL - Brasil
}

\begin{abstract}
O trabalho estuda o efeito da Lei de Responsabilidade Fiscal (LRF) sobre as finanças públicas dos municípios alagoanos. Fez-se a opção de trabalhar um referencial teórico menos formalista e mais crítico em relação à instauração da nova legislação. Na metodologia, manuseamos informações e dados disponíveis pela Secretaria do Tesouro Nacional, levantando estatísticas sobre aqueles municípios. Com base em índices de desempenho e capacidade fiscal, confirmou-se, no geral, o sucesso das pretensões da LRF no período 2000-10. Os cálculos indicam que esses limites foram alcançados, mas verificou-se que não garantem equilíbrio fiscal no longo prazo. Concluímos que o conceito de responsabilidade fiscal precisa ser rediscutido e essa condição não garante aos municípios capacidade de alocação e distribuição de recursos de forma mais eficiente, no quadro de mudanças rotineiras na política econômica nacional.
\end{abstract}

Palavras-chaves: Lei de Responsabilidade Fiscal; finanças públicas municipais; Alagoas.

Ley de Responsabilidad Fiscal: efectos y el impacto en los municipios de Alagoas en el período 2000-10

El trabajo estudia el efecto de la Ley de Responsabilidad Fiscal (LRF) en las finanzas públicas de los municipios de Alagoas. Había la opción de trabajar un marco teórico menos formalista y más crítico en relación con la introducción de una nueva legislación. En la metodología, manejamos la información y los datos disponibles por el Tesoro Nacional, elevando las estadísticas sobre esos municipios. Sobre la base de los índices de rendimiento y capacidad fiscal, se confirmó, en general, el éxito de las preten-

DOI: http://dx.doi.org/10.1590/0034-7612132652

Artigo recebido em 28 mar. 2014 e aceito em 17 dez. 2014.

(cc) BY-NC 
siones de la LRF en el período 2000-10. Los cálculos indican que se han alcanzado estos límites, pero que no garantiza a largo plazo se ha encontrado el equilibrio fiscal. Llegamos a la conclusión de que el concepto de responsabilidad fiscal necesita ser revisado y esta condición no garantiza la asignación de capacidad a los municipios y distribución de los recursos de manera más eficiente, como parte de los cambios de rutina en la política económica nacional.

Palabras clave: Ley de Responsabilidad Fiscal; finanzas públicas municipales; Alagoas.

Fiscal Responsibility Law: effects and impact on Alagoas' municipalities in the period 2000-10 This paper studies the effect of the law of Fiscal responsibility (LRF) on public finances of Alagoas' municipalities. There was the option of working a theoretical reference less formalist and more critical in relation to the introduction of the new legislation. In the methodology, we manipulated information and data available by the National Treasury Department, raising statistics on those municipalities. Based on fiscal performance and capacity ratings, it was confirmed, on the whole, the success of the pretensions of the LRF in the period 2000-2010. The calculations indicate that these limits were reached, but it was found that they do not guarantee long-term fiscal balance. We conclude that the concept of fiscal responsibility needs to be revisited and this condition does not warrant the municipalities the allocation and distribution capacity of resources more efficiently, in the context of routine changes in national economic policy.

KeYwords: Fiscal Responsibility Law; municipal public finance; Alagoas.

\section{Introdução}

Historicamente os municípios brasileiros buscaram maior autonomia financeira do poder central; tal conquista começou a ser vislumbrada a partir da segunda metade da década de 1980, principalmente em decorrência do processo de redemocratização do país que culminou com a promulgação da Constituição de 1988. Nela, os municípios foram definitivamente considerados entes federados e autônomos, condição que lhes possibilitou obter maior participação na distribuição dos recursos arrecadados.

Todavia, após a segunda metade da década de 1990, o governo federal buscou mecanismos de recompor suas finanças, como também alternativas para regular os entes subnacionais, com o intuito de manter a estabilização macroeconômica alcançada. Porém, o custo para os estados e municípios foi alto, parte dele decorrente da irresponsabilidade dos gestores públicos e, uma parcela significativa, devido a estratégias fiscais adotadas pelo Plano Real, cujos principais reflexos se deram no aumento da carga tributária e na centralização de recursos junto à esfera federal.

Destarte, a situação nos anos seguintes da promulgação da Constituição de 1988 e o impacto das medidas adotadas pela União demonstram que a descentralização financeira proposta foi minada logo após seu lançamento, visto que o interesse da União versa sobre uma maior centralização das receitas, que por sua vez garante maior eficácia das políticas econômicas adotadas e eficiência das metas e compromissos, principalmente, com os credores da dívida pública. 
Nesse contexto, surgiram leis regulatórias das finanças públicas, sendo a Lei Complementar no 101/2000, denominada Lei de Responsabilidade Fiscal (LRF), a que teve maior impacto sobre as finanças dos municípios brasileiros. Com a implantação da LRF, os municípios tiveram de buscar formas de se adequarem às limitações regulatórias impostas pela mesma e ajustarem a gestão fiscal-financeira às novas condicionalidades.

Assim, o trabalho visa analisar os impactos da Lei de Responsabilidade Fiscal sobre os municípios alagoanos, a fim de verificar se os mesmos cumpriram as metas básicas de legislação, bem como também como se deu o comportamento dos níveis de dependência de suas finanças públicas em relação às transferências governamentais. As informações utilizadas foram selecionadas a partir de dados da Secretaria do Tesouro Nacional (STN), base Finbra, e com essas informações foram utilizados diversos indicadores a fim de validar dados distorcidos. Elegendo os municípios que contemplavam informações completas e sólidas para toda a série, foram selecionadas 72 cidades, que embora não correspondam aos 102 municípios, não invalidam a proposta de análise, visto que esse grupo representou 90\% do PIB de Alagoas em 2010, conforme dados do IBGE. Assim, o objetivo preliminar constituiu no levantamento e sistematização dos dados referentes aos 102 municípios alagoanos, no período de 1999 a 2010, excluindo aqueles que não dispunham de dados para toda a série histórica ou que apresentem discrepâncias.

Destarte, o trabalho ficou dividido em cinco partes: esta breve introdução; a segunda parte trata da autonomia municipal pós-Constituição de 1988; a terceira analisa a Lei de Responsabilidade Fiscal fazendo uma contextualização de sua implementação; a quarta aborda as finanças públicas dos municípios alagoanos após a LRF entrar definidamente em vigor; por fim, as conclusões realizam um balanço geral dos principais e relevantes aspectos do trabalho.

\section{A autonomia municipal após a Constituição de 1988}

A Constituição Federal (CF) de 1988 foi um marco na democracia brasileira. A partir de sua promulgação os municípios ampliaram a participação no "bolo tributário brasileiro" e receberam novas atribuições. Ressalta-se que o movimento de autonomia fiscal municipal foi reduzido durante o regime militar, que buscou centralizar os recursos no governo central, via diminuição nos repasses do Fundo de Participação dos Estados (FPE) e Fundo de Participação dos Municípios (FPM). Assim, a partir de 1988, a nova CF trouxe consigo a missão de descentralizar os recursos sob o poder da União, como exposto por Boueri e colaboradores (2009:16).

Portanto, a reforma constitucional de 1988 concretizou a necessidade de maior autonomia de estados e municípios. Proporcionou a estados e municípios aumentos na participação da arrecadação tributária da União por meio da elevação dos coeficientes de distribuição do FPE e do FPM. Tal movimento acelerou o processo de redução do esforço fiscal da maioria dos estados e incrementou as iniciativas na disputa fiscal entre os mesmos para atração de investimentos e geração de empregos. 
A autonomia dos estados e municípios, a desconcentração dos recursos tributários disponíveis e as transferências de gastos da União foram alguns dos principais objetivos da nova Constituição. Ressaltam-se também os esforços das autoridades estaduais e municipais para a coibição da liberdade que o governo federal detinha para manipular as questões orçamentárias, interferindo na arrecadação de estados e municípios. Com as negociações, os estados expandiram suas receitas com a inclusão de novos tributos e aumento nos repasses dos antigos. O FPE correspondia, em 1968, a 5\% do Imposto de Renda (IR) e passa a representar 21,5\%, em 1993. Entretanto, o aumento mais significativo foi nas receitas municipais, $22,5 \%$.

Com as negociações que alimentaram a Constituição de 1988, houve um retorno ao sistema federativo descentralizado. ${ }^{1}$ Assim, Régis (2008) pontua que "o Brasil se tornou um dos países mais descentralizados do mundo. Desde 1988, foram criados mais de 1.200 municípios por causa da facilitação trazida pela Constituição de 1988". Ademais, três novos estados foram criados (Amapá, Roraima e Tocantins), comprovando os efeitos descentralizantes da nova Constituição.

Passado esse período inicial de adaptação às novas regras constitucionais, nos anos seguintes observaram-se aumentos nas responsabilidades municipais. Segundo Nazareth (2002), os municípios foram os maiores beneficiados na partilha dos recursos para áreas como Educação e Saúde. Ainda para a autora, esses benefícios se deram pelo aumento nas transferências federais, pelos incrementos na arrecadação própria e na melhoria da máquina fazendária. Em contrapartida, muitos autores defendem que os mecanismos de transferências só aumentaram o grau de distorções entre os municípios, prejudicando principalmente aqueles com maior estoque populacional. ${ }^{2}$

Apesar do aumento da participação dos estados no "bolo tributário" após a Constituição, para viabilizar o financiamento de gastos e investimentos em áreas sociais, a União instituiu as denominadas contribuições sociais, sem indicações de partilhas junto aos entes subnacionais. Com isso se instaurou um novo mecanismo de centralização fiscal, efetivamente utilizado pelo governo federal, principalmente na década de 1990. Vale ressaltar que a ampliação das transferências foi um importante reforço para a diminuição das desigualdades regionais e interestaduais, como pontua Bercovici (2003:158): “As transferências intergovernamentais de recursos são um instrumento de redistribuição de renda, com fundamento nos princípios da igualdade e da solidariedade, não um subsídio ou uma forma de caridade dos entes mais ricos para os mais pobres".

Todavia, as graves distorções macroeconômicas persistentes desde a década de 1980 provocaram mudanças nesse arranjo federativo. Buscando o equilíbrio macroeconômico, ensejou-se um novo arranjo federativo, como ressalta Lopreato (2013:179):

\footnotetext{
${ }^{1}$ Vale ressaltar que a constituição anterior a 1988, promulgada em 1967 durante o período ditatorial, era pautada na centralização financeira.

${ }^{2}$ Como os trabalhos de Oliveira (1995) e Baracho (2010).
} 
O novo federalismo alterou o relacionamento da União com os entes subnacionais e as articulações no interior dos próprios estados e municípios. O poder federal de controlar a política fiscal ganhou força, e o processo de descentralização, responsável por ampliar a presença de Municípios em lugar dos governos estaduais, trouxe modificações à dinâmica dos gastos públicos.

No bojo dessas transformações, a estabilidade monetária é alcançada com o Plano Real, por meio de uma série de mecanismos estabelecidos de controle das finanças públicas objetivando, também, maior controle sobre os orçamentos dos entes federados e manutenção da estabilização macroeconômica.

\section{A Lei de Responsabilidade Fiscal (LRF)}

A Lei de Responsabilidade Fiscal foi formulada e justificada como um programa de estabilização fiscal, fundamentada nos princípios do planejamento, transparência, controle e responsabilidade. O contexto econômico que antecede a LRF está diretamente ligado aos códigos de boas práticas de gestão disseminados pelo Fundo Monetário Internacional (FMI), que incluiu essa e outras exigências para a concessão de novos empréstimos ao país, depois de uma grave crise cambial em 1998-99.

A LRF estabelece, ainda, diretrizes para os três entes da federação, abrangendo sua atuação os três poderes (Executivo, Legislativo e Judiciário), bem como os Tribunais de Contas, estaduais e municipais. Em relação ao orçamento público e às técnicas de planejamento, a lei manteve os princípios constitucionais e as três peças fundamentais, Lei de Diretrizes Orçamentária (LDO), Lei Orçamentária Anual (LOA) e Plano Plurianual (PPA). A adoção desses três instrumentos fez parte das novas exigências do estabelecimento de uma programação financeira e adoção de cronogramas mensais de desembolso de recursos orçamentários. $\mathrm{O}$ objetivo maior foi interligar a execução orçamentária e o fluxo dos recursos financeiros programados (art. 8 da LRF).

Em relação à receita pública, a LRF delimitou-a mediante a previsão, arrecadação e renúncia. Destarte, estipulou que toda previsão deve seguir normas técnicas e legais, com análise dos três anos anteriores e estimativas para os anos seguintes; orientou os entes federados a uma gestão fiscal responsável, sob pena de não receberem as transferências voluntárias quando do não cumprimento dessa norma.

No tocante às despesas, a LRF foi mais incisiva e estabeleceu diversas regras. Em seus arts. 15 e 16, considera não autorizado, irregular ou lesivo ao patrimônio todo aumento de despesa que não possua estimativa de impacto orçamentário/financeiro. Ainda no art. 17, a LRF indica que as despesas consideradas obrigatórias deverão ter as estimativas e os impactos financeiros plenamente avaliados e não poderão interferir nas metas fiscais previstas, desconsiderando despesas com serviços de dívidas contraídas e reajustamentos na folha de pessoal (Brasil, 2000). 
O subitem de despesas destinado ao pagamento de pessoal recebeu uma atenção especial da LRF. Em seu art. 18 considera tais despesas como:

o somatório dos gastos do ente da Federação com os ativos, os inativos e os pensionistas, relativos a mandatos eletivos, cargos, funções ou empregos, civis, militares e de membros de Poder, com quaisquer espécies remuneratórias, tais como vencimentos e vantagens, fixas e variáveis, subsídios, proventos da aposentadoria, reformas e pensões, inclusive adicionais, gratificações, horas extras e vantagens pessoais de qualquer natureza, bem como encargos sociais e contribuições recolhidas pelo ente às entidades de previdência. (Brasil, 2000:17)

A despesa com gastos de pessoal passou então a obedecer limites estabelecidos para cada ente federado, ${ }^{3}$ a saber: União (50\%), estados (60\%) e municípios (60\%), utilizando como referência a receita corrente líquida ${ }^{4}$ e, assim, estratificando índices por poder e órgão, conforme a tabela 1 .

A LRF também reserva um item para a discussão das transferências voluntárias, entendidas como: "entrega de recursos correntes ou de capital a outro ente da Federação, a título de cooperação, auxílio ou assistência financeira, que não decorra de determinação constitucional, legal ou os destinados ao Sistema Único de Saúde” (Brasil, 2000:18).

\section{Tabela 1}

\section{Despesas de pessoal por poder e órgão (\% RCL)}

\begin{tabular}{|cccccc|}
\hline Esfera/ & & & \multicolumn{3}{c|}{ Ministério } \\
Poder & Executivo & Legislativo & Judiciário & Público & Total \\
União & 40,90 & 2,50 & 6,00 & 0,60 & 50,00 \\
Estados & 49,00 & 3,00 & 6,00 & 2,00 & 60,00 \\
Municípios & 54,00 & 6,00 & - & - & 60,00 \\
\hline
\end{tabular}

Fonte: Lei Complementar ㄲo101 (LRF).

\footnotetext{
${ }^{3}$ Segundo Fioravante e colaboradores (2006): "A Lei Complementar no 82/1995, conhecida como Lei Camata, em cumprimento ao artigo no 169 da Constituição, determinava à União, aos Estados e aos Municípios limitarem os gastos com pessoal a $60 \%$ da receita corrente líquida, em até três anos. Nesse período, ficavam vedados reajustes e aumentos salariais até o cumprimento do limite estabelecido. A Emenda Constitucional no 09/1998 permitiu a adoção de medidas para o enquadramento, com a possibilidade até mesmo de demitir servidores estáveis". Tal lei foi substituída pela LRF.

${ }^{4}$ Cálculo da receita utilizando como base a receita arrecadada no mês de referência e nos onze meses imediatamente anteriores (últimos 12 meses), considerando todas as receitas correntes e deduzindo as transferências legais, contribuições e dedução da receita para o Fundo de Manutenção e Desenvolvimento da Educação Básica e de Valorização dos Profissionais da Educação (Fundeb).
} 
No caso das transferências, os entes federados deveriam seguir os princípios orçamentários da CF 1988 (art. 167), e proibiram-se sanções às transferências destinadas a educação, saúde e assistência social.

Em relação aos níveis de endividamento, a LRF conceitua diversos tipos de dívida, a consolidada (ou fundada), a mobiliária e as operações de crédito, sendo a primeira definida como "o montante total, apurado sem duplicidade, das obrigações financeiras do ente da Federação, assumidas em virtude de leis, contratos, convênios ou tratados e da realização de operações de crédito, para amortização em prazo superior a doze meses" (Brasil, 2000).

A dívida mobiliária foi conceituada como títulos emitidos pela União, Banco Central, estados e municípios. No que se refere às operações de crédito, a LRF estabelece:

o compromisso financeiro assumido em razão de mútuo, abertura de crédito, emissão e aceite de título, aquisição financiada de bens, recebimento antecipado de valores provenientes da venda a termo de bens e serviços, arrendamento mercantil e outras operações assemelhadas, inclusive com o uso de derivativos financeiros. (Brasil, 2000:20)

Quanto aos limites para endividamento, a LRF não os indicou, atribuindo a responsabilidade ao Senado Federal. Quanto às operações de crédito, a lei prevê autorização da LOA e proíbe, terminantemente, operações de crédito entre entes da federação, ${ }^{5}$ bem como o refinanciamento ou a postergação de dívida anteriormente contraída.

Os quesitos transparência, controle e fiscalização são núcleos centrais da LRF. Os principais instrumentos de transparência são "os planos, orçamentos e leis de diretrizes orçamentárias; as prestações de contas e o respectivo parecer prévio; o Relatório Resumido da Execução Orçamentária e o Relatório de Gestão Fiscal; e as versões simplificadas desses documentos" (Brasil, 2000).

Ademais, o incentivo à participação popular também foi manifestado na lei, e seria alcançado através da realização das audiências públicas durante a elaboração dos planos da lei de diretrizes e dos orçamentos.

Segundo Riani (2009), os encargos da dívida pública federal representam o principal item de despesa da União, em que os recursos destinados a tais despesas representaram, em 2006, sete vezes os gastos com saúde e educação somados, 20 vezes o gasto com segurança e 156 vezes o valor dos investimentos em ciência e tecnologia. Ainda segundo o autor, a dívida pública é a principal causadora da elevação da carga tributária, consumindo quase 30\% de todo o montante arrecadado no país.

Com maior disciplina e rigor fiscal, os estados e municípios tiveram de adequar suas finanças à nova legislação de maneira indiscriminada. Passados alguns anos após a pro-

\footnotetext{
${ }^{5}$ Segundo o Art. 35: "É vedada a realização de operação de crédito entre um ente da federação, diretamente ou por intermédio de fundo, autarquia, fundação ou empresa estatal dependente, e outro, inclusive suas entidades da administração indireta, ainda que sob a forma de novação, refinanciamento ou postergação de dívida contraída anteriormente" (Brasil, 2000).
} 
mulgação da LRF, alguns trabalhos demonstram os impactos nas finanças de pequenos municípios. Gerigk e colaboradores (2014), por exemplo, analisam os pequenos municípios paraenses. Chieza (2008), por sua vez, aborda a evolução das finanças públicas do Rio Grande do Sul.

Assim, como recomenda Corbari (2008), é relevante um estudo mais aprofundado sobre finanças públicas municipais e os efeitos da LRF sobre os pequenos municípios, principalmente visto que a literatura brasileira é carente de estudos sociais, políticos e econômicos que investiguem as causas do endividamento municipal no Brasil. Desse modo, buscando contornar esse problema e contribuir de forma muito marginal, torna-se válido um estudo dessa natureza sobre os municípios alagoanos abordando os impactos de LRF nas finanças públicas.

\section{As finanças públicas nos municípios alagoanos após a implantação da LRF}

Na nova legislação que estabeleceu regras de maior controle para as finanças públicas subnacionais no país, o capítulo da receita pública recebeu destaque especial. Um dos passos importantes foi tornar obrigatória a previsão de arrecadação de todos os tributos e vinculando a expansão e criação de novas despesas ao prévio estabelecimento das correspondentes fontes de receitas. Dessa forma, a obtenção de níveis de receitas adequados ao respectivo volume de despesas se tornou um desafio para os gestores públicos, especialmente para aqueles que atuam na esfera municipal.

No caso dos municípios alagoanos, por exemplo, a receita orçamentária total cresceu em termos nominais 3,39 vezes, entre os anos 2000 e $2010 .{ }^{6}$ Se por um lado os municípios com até 5 mil habitantes apresentaram a menor elevação, ${ }^{7}$ aqueles com população até 20 mil pessoas apresentaram maior índice de crescimento da receita, 3,75 vezes. ${ }^{8}$

A LRF estabeleceu, como parâmetro de referência para os cálculos dos limites com as despesas com pessoal e dívida consolidada líquida, a Receita Corrente Líquida (RCL). Sua composição demonstra a extrema dependência dos municípios alagoanos dos recursos oriundos das transferências das demais esferas de governo. No ano de implantação da LRF, o indicador de dependência (ID) ${ }^{9}$ apontava que $85,78 \%$ da RCL era formado pelas transferências dos governos federal e estadual. Esse percentual pouco foi alterado durante o período analisado nesta pesquisa, chegando, em 2010, com uma participação de 83,30\%. Após a implantação da LRF, ocorreu uma redução da participação das receitas de transferências correntes na RCL

\footnotetext{
${ }^{6}$ Conforme seleção de dados já apresentada na introdução do trabalho.

${ }^{7}$ Para esse grupo, o crescimento da receita orçamentária foi de 2,7 vezes no período supracitado.

${ }^{8}$ Esse fato provocou uma desconcentração da receita pública, visto que no ano 2000 apenas as duas cidades com população superior a 100 mil habitantes detinham 44,15\% de toda a receita orçamentária, sendo, em 2010, esse índice de participação reduzido para 40,90\%.

${ }^{9} \mathrm{O}$ indicador de dependência mede o grau de dependência do município em relação aos recursos de outras esferas de governo. É calculado pela razão entre as transferências constitucionais e a receita corrente líquida (RCL).
} 
dos municípios alagoanos, porém tal redução ainda está longe de afetar o grau de dependência dessas cidades das transferências intergovernamentais.

A redução do grau de dependência foi motivada pelo aumento da arrecadação tributária própria municipal, visto que, em 2000, 15,78\% das cidades alagoanas não arrecadavam IPTU de maneira significativa e 5,56\% não podiam dizer que contavam com recursos do ISS. No ano de 2010, todos os municípios alagoanos arrecadaram ISS e apenas 2,78\% não contaram com IPTU. Esses dois impostos respondem por mais de 50\% da receita tributária municipal. Dessa forma, o crescimento da arrecadação desses municípios favoreceu o aumento da participação da receita tributária na receita orçamentária total de 10,03\%, em 2000, para 10,30\%, em 2010. Esse último índice ainda está bem abaixo da média nacional, que é de $17,21 \%$, indicando que existe um potencial tributário ainda não explorado pelos municípios do estado de Alagoas. ${ }^{10}$

Entre os componentes das transferências correntes, o FPM é o que possui maior participação relativa, representando mais de $40 \%$ do volume total recebido pelos municípios brasileiros. Devido à sua importância, qualquer oscilação ocorrida em seu repasse afeta diretamente o desempenho das finanças dos municípios alagoanos, algo não tão diferente do restante da maioria dos municípios pequenos brasileiros.

A título de exemplo, de como as finanças públicas municipais ficam vulneráveis diante das mudanças na política econômica nacional, em termos nominais, no ano de 2009, o volume de FPM repassado aos municípios do estado de Alagoas foi 3,76\% menor do que o ano anterior e, em termos reais, a redução foi ainda mais elevada, atingindo 8,21\%. O ano de 2010, apesar de apresentar um crescimento nominal da ordem de 7,66\%, em termos reais alcançou elevação de apenas 2,73\%, índices bastante modestos se comparados com os verificados no biênio anterior, cuja média real atingiu 15,96\%. Esse movimento decorreu das medidas adotadas pelo governo federal visando minimizar os impactos da crise financeira global desencadeada no ano de 2008. Um dos pilares desse processo de enfrentamento foi a redução das alíquotas do IPI e a revisão da tabela do IR. Sendo ambos os tributos constituintes do FPM, qualquer modificação em seus índices provoca um efeito direto nas contas públicas municipais. Pode-se afirmar, então, que as medidas anticíclicas adotadas pela União afetaram negativamente um dos principais componentes da receita orçamentária municipal.

\subsection{Desempenho e evolução das despesas públicas dos municípios alagoanos}

A LRF estabeleceu uma série de critérios e restrições para impedir o crescimento das despesas públicas a níveis superiores ao efetivamente arrecadado, buscando dessa forma evitar o endividamento público.

\footnotetext{
${ }^{10} \mathrm{O}$ baixo índice de participação da receita tributária demonstra a falta de uma base fiscal que sustente as atividades de boa parte dos municípios alagoanos, tendo em vista que no ano de 2010 aproximadamente 56\% das cidades do estado de Alagoas não arrecadavam o suficiente sequer para pagar suas câmaras de vereadores, o que levava à complementação dos recursos por meio do uso de recursos correntes transferidos.
} 
Para facilitar o entendimento, adotamos a divisão em cinco grupos dos municípios alagoanos pelo tamanho da população. ${ }^{11}$ Essa divisão pode ser visualizada na tabela 3. Assim, entre os anos de 2000 e 2010, os gastos públicos do estado cresceram 3,57 vezes, tendo os municípios dos grupos 3 e 5 uma expansão superior a 3,64 vezes, superando a média estadual. Analisando a variação acumulada das despesas orçamentárias, é possível perceber que, com exceção do ano de 2008, elas superaram a variação das receitas orçamentária dos municípios alagoanos nos demais exercícios financeiros.

A decomposição das despesas orçamentárias dos municípios analisados nesta pesquisa, feita na tabela 2, permite identificar que houve uma expansão dos gastos correntes e uma redução dos gastos com capital. No ano 2000, as despesas com a manutenção da máquina pública representavam 89,71\% do total dos gastos. Em 2010, esse índice cresceu para 91,49\%.

Nesse contexto, destaca-se a expressiva elevação dos gastos com pessoal, que representavam, no ano de implantação da LRF, 32,24\% das despesas totais. Em 2010 eles passaram a responder por $47,39 \%$ das despesas totais. Os resultados obtidos apontam que esse índice cresceu de forma inversa ao tamanho dos municípios, como aqueles enquadrados no grupo 1 $(58,56 \%)$.

Os resultados extraídos da amostra analisada apontam que entre 2000 e 2010 o total dos gastos correntes cresceu 366,14\% e com pessoal, 571,80\%. Portanto, índices de crescimento bem superiores aos da despesa e receita pública totais. Esses fatos corroboram a afirmação de que a implantação da LRF não foi suficiente para promover a redução dos gastos correntes e, especialmente, os destinados às despesas com pessoal e encargos no caso dos municípios do estado de Alagoas.

Os dados da tabela 2 evidenciam, ainda, uma tendência de redução dos gastos voltados aos investimentos públicos no período aqui analisado. Essa modalidade de gasto apresentou um comportamento bastante instável, diferentemente dos gastos correntes e com pessoal, que cresceram quase de forma constante, sinalizando que existiu um movimento de promoção do ajuste fiscal por meio de cortes nos investimentos públicos. ${ }^{12}$

Para Menezes e Toneto Jr. (2006), a redução do nível de investimentos pode afetar negativamente a provisão futura de bens e serviços principalmente na esfera municipal. A supremacia e a rigidez dos gastos com pessoal sobre os investimentos públicos podem ser verificadas no gráfico 1 . Observa-se que no ano 2000 a despesa com pessoal era 2,75 vezes maior do que os dispêndios com investimentos públicos e, para 2010, essa relação atingiu o patamar de 6,05 vezes.

\footnotetext{
${ }^{11}$ Utilizando como critério o Censo 2010.

${ }^{12} \mathrm{O}$ ajuste fiscal viabilizado por meio da redução dos investimentos públicos se intensificou a partir de 2008, justamente durante o início da crise financeira internacional. Antes da crise, os investimentos representavam, em média, $10,79 \%$ dos gastos totais, passando para 6,7\% após seu início.
} 
Tabela 2

Composição da despesa pública dos municípios alagoanos 2000-10

\begin{tabular}{|ccccccc|}
\hline Ano & Pessoal & $\begin{array}{c}\text { Outras desp. } \\
\text { Correntes }\end{array}$ & $\begin{array}{c}\text { Total } \\
\text { Correntes }\end{array}$ & Investimentos & $\begin{array}{c}\text { Outras desp. } \\
\text { Capital }\end{array}$ & $\begin{array}{c}\text { Total } \\
\text { Capital }\end{array}$ \\
\hline 2000 & 32,24 & 57,47 & 89,71 & 8,60 & 1,69 & 10,29 \\
2001 & 35,37 & 53,90 & 89,26 & 7,92 & 2,82 & 10,74 \\
2002 & 39,36 & 43,04 & 82,40 & 15,89 & 1,71 & 17,60 \\
2003 & 41,98 & 44,33 & 86,31 & 11,22 & 2,47 & 13,69 \\
2004 & 42,10 & 43,59 & 85,70 & 12,73 & 1,57 & 14,30 \\
2005 & 43,58 & 47,12 & 90,70 & 7,54 & 1,76 & 9,30 \\
2006 & 41,22 & 45,21 & 86,42 & 11,20 & 2,38 & 13,58 \\
2007 & 41,06 & 45,86 & 86,92 & 10,38 & 2,70 & 13,08 \\
2008 & 44,21 & 46,46 & 90,67 & 6,40 & 2,94 & 9,33 \\
2009 & 45,13 & 45,61 & 90,74 & 7,01 & 2,25 & 9,26 \\
2010 & 47,39 & 44,10 & 91,49 & 6,72 & 1,79 & 8,51 \\
\hline
\end{tabular}

Fonte: Elaborada com base nos dados do Finbra/STN.

Gráfico 1

Razão despesa com pessoal e investimentos dos municípios alagoanos (2000-10)

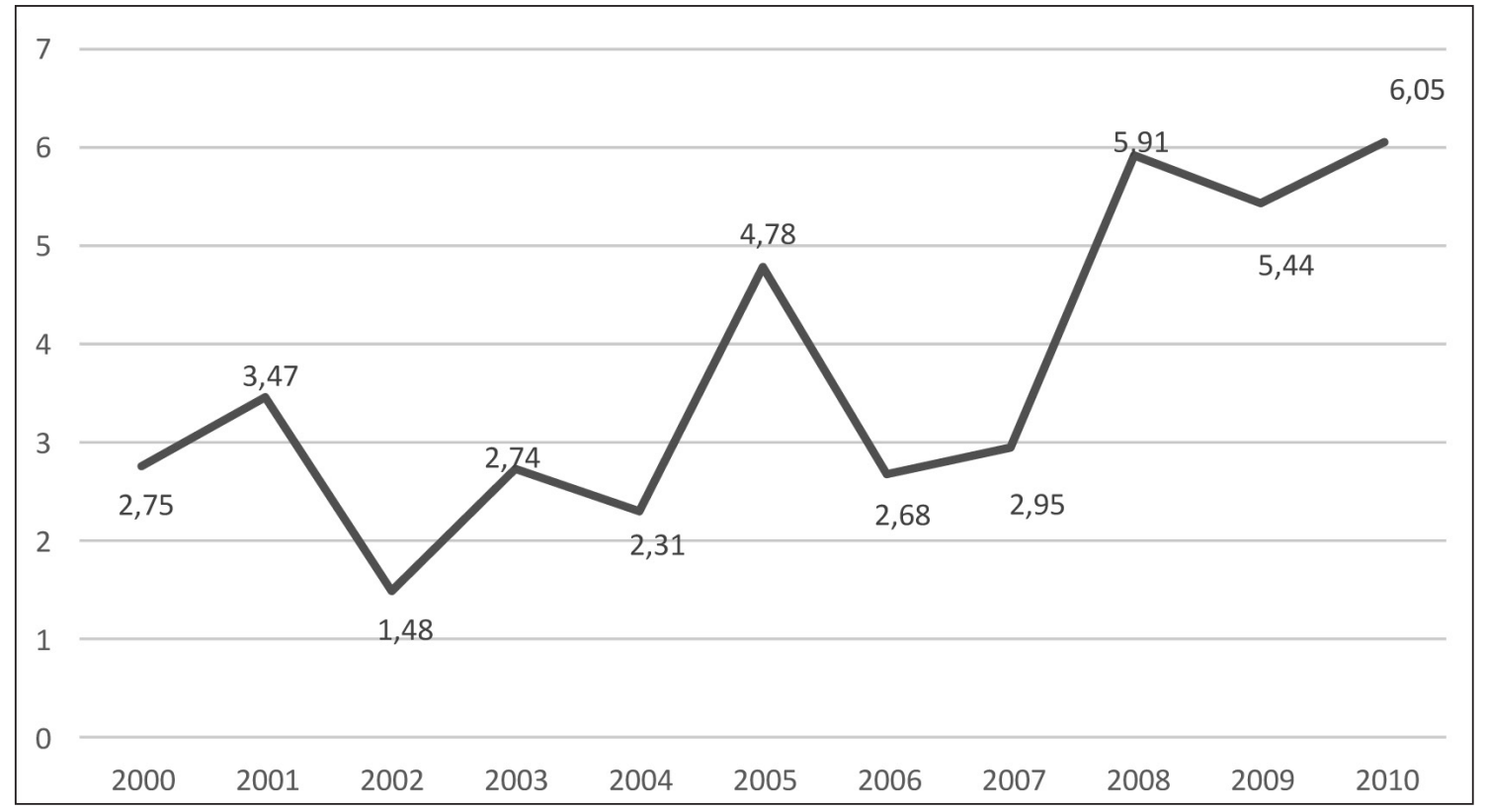

Fonte: Elaborado com base nos dados do Finbra/STN. 
Por sua importância na composição dos gastos públicos, as despesas com pessoal mereceram atenção especial na elaboração da LRF. Limitaram-se então os gastos com pessoal em 60\% da RCL. Para aferirmos esse resultado, utilizamos como base o Índice de Pessoal (IP), calculado pela razão entre os gastos com pessoal e a RCL.

Os resultados apresentados na tabela 3 demonstram de forma consolidada que os municípios alagoanos cumpriram o limite estabelecido na LRF. Todavia, observa-se que houve uma elevação da relação DP/RCL, passando de 41,55\%, no ano 2000, para 51,19\%, no ano de 2010. Esse índice representa $85,32 \%$ do limite máximo permitido. No ano 2000, esse patamar atingiu apenas $69,25 \%$. Os dados estatísticos demonstram ainda que $56 \%$ do crescimento da RCL foram utilizados para compensar a elevação dos gastos com pessoal.

Tabela 3

Despesa com pessoal/RCL dos municípios alagoanos 2000-10 (\%)

\begin{tabular}{|cccccccccc|}
\hline Ano & $\begin{array}{c}\text { Até } 5.000 \\
\text { habitantes }\end{array}$ & $\begin{array}{c}\text { De 5.001 } \\
\text { a 20.000 } \\
\text { habitantes }\end{array}$ & $\begin{array}{c}\text { De 20.001 } \\
\text { a 100.000 } \\
\text { habitantes }\end{array}$ & $\begin{array}{c}\text { De 100.001 } \\
\text { a 500.000 } \\
\text { habitantes }\end{array}$ & $\begin{array}{c}\text { Mais de } \\
500.000 \\
\text { habitantes. }\end{array}$ & Total & Limite & Legal & Comprometido \\
\hline 2000 & 45,45 & 43,15 & 45,46 & 39,76 & 35,72 & 41,55 & 60 & 69,25 \\
2001 & 39,02 & 46,25 & 45,35 & 35,89 & 48,38 & 45,48 & 60 & 75,81 \\
2002 & 40,02 & 40,95 & 41,14 & 34,70 & 41,93 & 40,87 & 60 & 68,11 \\
2003 & 44,00 & 44,56 & 43,26 & 37,35 & 41,90 & 42,57 & 60 & 70,95 \\
2004 & 42,98 & 44,88 & 42,62 & 37,23 & 41,32 & 42,17 & 60 & 70,29 \\
2005 & 45,45 & 46,43 & 42,99 & 38,51 & 41,21 & 42,53 & 60 & 70,88 \\
2006 & 47,71 & 47,93 & 44,92 & 39,13 & 40,44 & 44,31 & 60 & 73,85 \\
2007 & 49,48 & 49,14 & 46,44 & 42,65 & 37,34 & 43,57 & 60 & 72,61 \\
2008 & 49,55 & 48,99 & 45,12 & 42,34 & 37,51 & 43,11 & 60 & 72,59 \\
2009 & 56,84 & 54,92 & 53,33 & 43,03 & 47,61 & 50,94 & 60 & 84,90 \\
2010 & 61,80 & 55,16 & 53,87 & 48,12 & 45,93 & 51,19 & 60 & 85,32 \\
\hline
\end{tabular}

Fonte: Elaborada com base nos dados do Finbra/STN.

Constatamos, ainda, que no período 2000-10 ocorreu uma homogeneidade dos gastos e uma tendência de crescimento do gasto médio com pessoal, ocasionando acomodação dos índices em níveis mais elevados. ${ }^{13}$ No ano 2000, por exemplo, apenas quatro municípios (5,56\% do total da amostra) apresentavam índices de gastos com pessoal superiores a 60\% da RCL. Em 2010, o desequilíbrio atingiu 20 municípios (27,78\% do total analisado).

\footnotetext{
${ }^{13}$ Tal tendência também foi verificada por Chieza (2008) ao analisar a situação dos municípios do estado do Rio Grande do Sul.
} 
Percebe-se, portanto, que os municípios que estavam executando despesas acima do limite estabelecido no ano 2000 se ajustaram já no ano seguinte. Porém, comparando os resultados individuais obtidos para os anos 2000 e 2010, em 85\% deles passaram a gastar uma parcela maior da RCL com as despesas de pessoal. Tais efeitos também foram apontados nos estudos de Giuberti (2005), Fioravante e colaboradores (2006) e Corbari (2008).

Maior crescimento ocorreu nos anos de 2009 e 2010, ocasionado por uma desaceleração no crescimento da RCL nesse período. Até 2008, o crescimento médio anual da RCL era de 19,39\%. Já no biênio 2009-10 esse índice foi reduzido para 10,46\%. Tal queda foi ocasionada por uma forte retração do crescimento dos repasses do FPM, visto que entre os anos 2000 e 2008 o crescimento médio anual foi da ordem de 18,27\%, enquanto a variação do FPM foi de apenas $1,59 \%$.

O gráfico 2 apresenta a variação anual da RCL e das despesas com pessoal. Com exceção dos anos 2002, 2004 e 2007, em todos os demais o crescimento dos gastos com pessoal superou o da RCL. Entre os anos 2000 e 2010, a RCL cresceu numa média anual de 17,60\%, enquanto as despesas com pessoal evoluíram 19,86\%. Dessa forma, uma parcela cada vez maior da RCL foi direcionada a essa modalidade de gastos em detrimento, principalmente, dos investimentos públicos.

\section{Gráfico 2 \\ Variação percentual da Receita Corrente Líquida ( $R C L)$ e das despesas com pessoal dos municípios alagoanos (2000-10)}

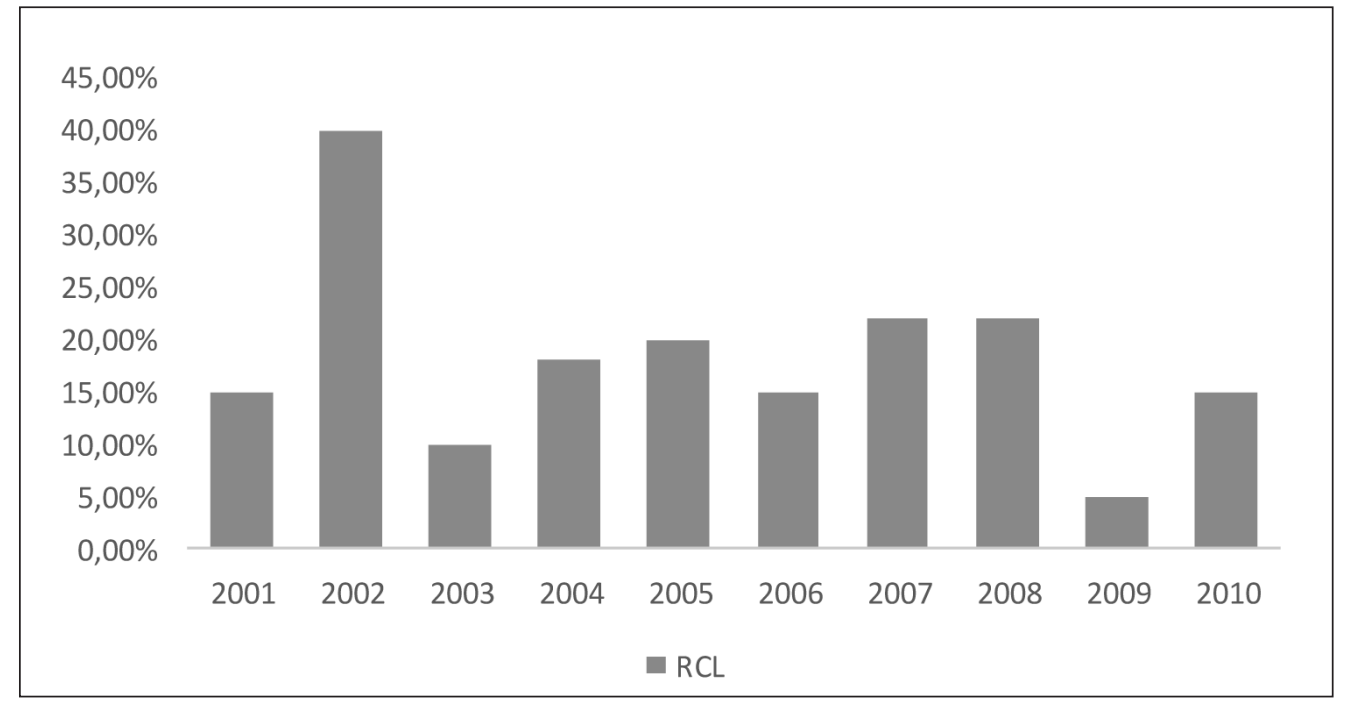

Fonte: Elaborado com base nos dados do Finbra/STN.

Apesar de a queda da RCL provocada pela redução do FPM afetar todos os municípios, o impacto desse movimento teve magnitudes distintas dentro dos grupos de municípios, pois 
se nota que aqueles com população até 5 mil habitantes foram os que mais aumentaram seus resultados do Índice de Pessoal (IP). Comparando o indicador para os anos de 2008 e 2010, verifica-se que houve uma elevação de 27,98\%. Dessa forma, os municípios do grupo 1 foram os únicos que ultrapassaram o limite de $60 \%$ da RCL estabelecido pela LRF.

A tabela 4 permite observar o percentual de municípios que dentro de cada grupo ultrapassou tanto o limite prudencial ${ }^{14}$ como o limite legal imposto pela LRF. Entre 2000 e 2008 ocorreu uma significativa redução do número de municípios que haviam ultrapassado o limite de 60\% da RCL. Todavia, nos exercícios financeiros 2009 e 2010, o índice de municípios em situação irregular atingiu níveis inéditos e crescentes.

Observa-se, ainda, que, quanto mais dependente das transferências governamentais, maiores dificuldades apresenta o município em cumprir os parâmetros estabelecidos pela LRF. No ano de 2010, mais de 70\% dos municípios alagoanos que apresentaram situação de não conformidade com os limites da LRF tinham menos de 20 mil habitantes. Esse percentual de participação se reduz ao mesmo tempo que aumenta o contingente populacional.

Tabela 4

Percentual de municípios com relação despesa com pessoal/RCL acima do limite prudencial de $57 \%$ e do limite máximo da LRF de $60 \%$

\begin{tabular}{|c|c|c|c|c|c|c|c|c|c|c|c|c|}
\hline \multirow[t]{2}{*}{ Ano } & \multicolumn{2}{|c|}{$\begin{array}{l}\text { Até } 5.000 \\
\text { habitantes }\end{array}$} & \multicolumn{2}{|c|}{$\begin{array}{c}\text { De } 5.001 \text { a } 20.000 \\
\text { habitantes }\end{array}$} & \multicolumn{2}{|c|}{$\begin{array}{l}\text { De } 20.001 \\
\text { a } 100.000 \\
\text { habitantes }\end{array}$} & \multicolumn{2}{|c|}{$\begin{array}{c}\text { De } 100.001 \\
\text { a } 500.00 \\
\text { habitantes }\end{array}$} & \multicolumn{2}{|c|}{$\begin{array}{c}\text { Mais de } 500.00 \\
\text { habitantes. }\end{array}$} & \multicolumn{2}{|c|}{ Total } \\
\hline & $>57 \%$ & $>60 \%$ & $>57 \%$ & $>60 \%$ & $>57 \%$ & $>60 \%$ & $>57 \%$ & $>60 \%$ & $>57 \%$ & $>60 \%$ & $>57 \%$ & $>60 \%$ \\
\hline 2001 & $0 \%$ & $0 \%$ & $13,51 \%$ & $8,11 \%$ & $7,14 \%$ & $3,57 \%$ & $0 \%$ & $0 \%$ & $0 \%$ & $0 \%$ & $9,72 \%$ & $5,56 \%$ \\
\hline 2002 & $0 \%$ & $0 \%$ & $2,70 \%$ & $0,00 \%$ & $3,57 \%$ & $0 \%$ & $0 \%$ & $0 \%$ & $0 \%$ & $0 \%$ & $2,78 \%$ & $0,00 \%$ \\
\hline 2003 & $0 \%$ & $0 \%$ & $2,70 \%$ & $2,70 \%$ & $7,14 \%$ & $7,14 \%$ & $0 \%$ & $0 \%$ & $0 \%$ & $0 \%$ & $4,17 \%$ & $4,17 \%$ \\
\hline 2004 & $0 \%$ & $0 \%$ & $2,70 \%$ & $2,70 \%$ & $0 \%$ & $0 \%$ & $0 \%$ & $0 \%$ & $0 \%$ & $0 \%$ & $1,39 \%$ & $1,39 \%$ \\
\hline 2005 & 0\% & $0 \%$ & $5,41 \%$ & $0,00 \%$ & $0 \%$ & $0 \%$ & $0 \%$ & $0 \%$ & $0 \%$ & $0 \%$ & $2,78 \%$ & $0,00 \%$ \\
\hline 2006 & $20 \%$ & $20 \%$ & $8,11 \%$ & $2,70 \%$ & $7,14 \%$ & $3,57 \%$ & $0 \%$ & $0 \%$ & $0 \%$ & $0 \%$ & $8,33 \%$ & $4,17 \%$ \\
\hline 2007 & $0 \%$ & $0 \%$ & $8,11 \%$ & $0,00 \%$ & $7,14 \%$ & $3,57 \%$ & $0 \%$ & $0 \%$ & $0 \%$ & $0 \%$ & $6,94 \%$ & $1,39 \%$ \\
\hline 2008 & $0 \%$ & $0 \%$ & $5,41 \%$ & $2,70 \%$ & $3,57 \%$ & $3,57 \%$ & $0 \%$ & $0 \%$ & $0 \%$ & $0 \%$ & $4,17 \%$ & $2,78 \%$ \\
\hline 2009 & $60 \%$ & $40 \%$ & $40,54 \%$ & $21,62 \%$ & $25,00 \%$ & $10,71 \%$ & $0 \%$ & $0 \%$ & $0 \%$ & $0 \%$ & $34,72 \%$ & $18,06 \%$ \\
\hline 2010 & $60 \%$ & $60 \%$ & $35,14 \%$ & $27,03 \%$ & $35,71 \%$ & $25,00 \%$ & $0 \%$ & $0 \%$ & $0 \%$ & $0 \%$ & $36,11 \%$ & $27,78 \%$ \\
\hline
\end{tabular}

Fonte: Elaborada com base nos dados do Finbra/STN.

\footnotetext{
${ }^{14} \mathrm{O}$ município ao atingir esse limite deve adotar medidas de ajustes visando evitar o descumprimento do limite legal de $60 \%$ da RCL.
} 
Além dos problemas enfrentados com os repasses do FPM, os municípios alagoanos também foram afetados pela política de reajuste do salário mínimo, definida exclusivamente pelo governo federal nos últimos anos. O efeito de tal política foi analisado pela Confederação Nacional dos Municípios (CNM), no ano de 2009, em trabalho intitulado "O aumento do salário mínimo e o seu impacto nas contas municipais". Tal análise apontou que o aumento de $12,05 \%$ no salário mínimo provocava crescimento de $26,21 \%$ no número de municípios que ultrapassavam o limite de gastos com pessoal imposto pela LRF.

\subsection{A dívida consolidada líquida}

A Resolução no 20 do Senado Federal estabeleceu o mês de maio de 2005 como prazo máximo para que os municípios se adequassem e cumprissem o limite de endividamento estabelecido. Todavia, para uma mensuração adequada da evolução da dívida dos municípios do estado de Alagoas, é fundamental a análise do desempenho deles durante todo o período de vigência da LRF, objetivando identificar a evolução do comportamento dos respectivos indicadores orçamentários dentro dos limites estabelecidos.

O limite de endividamento dos municípios brasileiros estabelecido na Resolução noํㅡㄴ 40 do Senado Federal foi de $120 \%$ da RCL. Pela análise da tabela 4, é possível observar que os municípios alagoanos apresentaram, durante o período analisado, uma situação bastante confortável em relação ao cumprimento ao limite estabelecido. No ano de 2000, a relação DCL/RCL era de 63,12\%, representando um comprometimento de 52,60\% da meta estabelecida. Para 2010 esse índice foi de apenas 5,19\%, comprometendo somente 4,33\% do limite máximo. ${ }^{15}$

Tais resultados são compatíveis com aqueles encontrados por Menezes e Toneto Jr. (2006) ao analisarem a situação do endividamento municipal em nível nacional, sinalizando que o limite de $120 \%$ da RCL está bem distante da realidade da maioria dos municípios brasileiros. Esses resultados corroboram a hipótese de que os municípios alagoanos estão cumprindo o limite de endividamento imposto após a implantação da LRF.

No período em análise, percebeu-se uma redução do índice de endividamento em todas as faixas populacionais, merecendo destaque, nesse contexto, o fato de a cidade de Maceió, além de concentrar mais de $80 \%$ do montante total da dívida do estado nos anos de 2000 e 2001 , ter sido a única que apresentou resultados superiores ao limite de $120 \%$ da RCL, com um desempenho da ordem de 173,02\% e 137,03\%, respectivamente.

\footnotetext{
${ }^{15}$ Fioravante e colaboradores (2006), ao analisar o desempenho do endividamento municipal em nível nacional, consideraram que o limite estabelecido pelo Senado Federal estava muito acima da realidade da maioria dos municípios brasileiros, situação que para os autores sinalizava um erro de calibragem, e que o limite definido visou atender aos grandes municípios, como foi o caso da cidade de São Paulo, que centralizava a maior parcela do endividamento total.
} 
Tabela 5

Razão: dívida consolidada líquida/receita corrente líquida (2000-10)

\begin{tabular}{|c|c|c|c|c|c|c|c|c|}
\hline Ano & $\begin{array}{l}\text { Até } 5.000 \\
\text { habitantes }\end{array}$ & $\begin{array}{c}\text { De } 5.001 \\
\text { a } 20.000 \\
\text { habitantes }\end{array}$ & $\begin{array}{l}\text { De } 20.001 \\
\text { a } 100.000 \\
\text { habitantes }\end{array}$ & $\begin{array}{c}\text { De } \\
100.001 \mathrm{a} \\
500.000 \\
\text { habitantes }\end{array}$ & $\begin{array}{c}\text { Mais de } \\
500.000 \\
\text { habitantes }\end{array}$ & Total & Limite & Comprometido \\
\hline 2000 & $-12,23 \%$ & $16,51 \%$ & $15,15 \%$ & $11,65 \%$ & $173,02 \%$ & $63,12 \%$ & $120 \%$ & $52,60 \%$ \\
\hline 2001 & $-19,37 \%$ & $15,48 \%$ & $12,41 \%$ & $6,93 \%$ & $137,30 \%$ & $50,01 \%$ & $120 \%$ & $41,68 \%$ \\
\hline 2002 & $-0,10 \%$ & $11,15 \%$ & $11,66 \%$ & $8,86 \%$ & $88,96 \%$ & $37,58 \%$ & $120 \%$ & $31,31 \%$ \\
\hline 2003 & $-15,60 \%$ & $11,07 \%$ & $10,55 \%$ & $7,43 \%$ & $70,87 \%$ & $30,91 \%$ & $120 \%$ & $25,76 \%$ \\
\hline 2004 & $-15,25 \%$ & $10,91 \%$ & $9,61 \%$ & $29,55 \%$ & $85,67 \%$ & $37,97 \%$ & $120 \%$ & $31,65 \%$ \\
\hline 2005 & $0,70 \%$ & $11,41 \%$ & $9,83 \%$ & $21,75 \%$ & $65,27 \%$ & $29,48 \%$ & $120 \%$ & $24,57 \%$ \\
\hline 2006 & $-5,28 \%$ & $9,65 \%$ & $8,05 \%$ & $8,69 \%$ & $52,57 \%$ & $23,27 \%$ & $120 \%$ & $19,39 \%$ \\
\hline 2007 & $-7,24 \%$ & $3,10 \%$ & $9,42 \%$ & $-19,36 \%$ & $36,33 \%$ & $15,19 \%$ & $120 \%$ & $12,66 \%$ \\
\hline 2008 & $-4,32 \%$ & $-0,55 \%$ & $5,13 \%$ & $-22,98 \%$ & $25,31 \%$ & $8,34 \%$ & $120 \%$ & $6,95 \%$ \\
\hline 2009 & $-5,10 \%$ & $4,55 \%$ & $10,10 \%$ & $-20,07 \%$ & $22,94 \%$ & $10,64 \%$ & $120 \%$ & $8,87 \%$ \\
\hline 2010 & $-4,21 \%$ & $0,62 \%$ & $8,14 \%$ & $-17,45 \%$ & $9,78 \%$ & $5,19 \%$ & $120 \%$ & $4,33 \%$ \\
\hline
\end{tabular}

Fonte: Elaborada com base nos dados do Finbra/STN.

Todavia, a partir do ano de 2002, a capital do estado iniciou uma significativa trajetória de ajuste, fazendo com que o nível de endividamento declinasse de forma quase constante, atingindo em 2010 o índice de 9,78\% da RCL. Nesse ano, sua participação na dívida total foi de $61,17 \%$, o menor patamar verificado no período analisado, o que aponta que ocorreu, portanto, uma desconcentração do endividamento durante a vigência da LRF.

Apesar de o endividamento líquido ter sido diminuído de forma considerável, as despesas com o serviço da dívida pública dos municípios alagoanos passaram a consumir uma parcela cada vez maior da RCL. No ano 2000, a razão serviço da dívida/RCL era de 1,54\%; em 2010 ela passou para 2,20\%, um crescimento de 42,86\% (gráfico 3). Resultados semelhantes foram obtidos no estudo de Menezes e Toneto Jr. (2006). Em Alagoas, apenas os municípios dos grupos acima de 50 mil habitantes apresentaram redução nesse índice, em todos os demais ocorreu elevação significativa. Vale destacar que, após a implantação da LRF, tais despesas passaram a ser consideradas prioritárias, não sendo objeto de cortes de gastos ou limitação de empenhos. 
Gráfico 3

Razão serviço da dívida/RCL dos municípios alagoanos (2000-10)

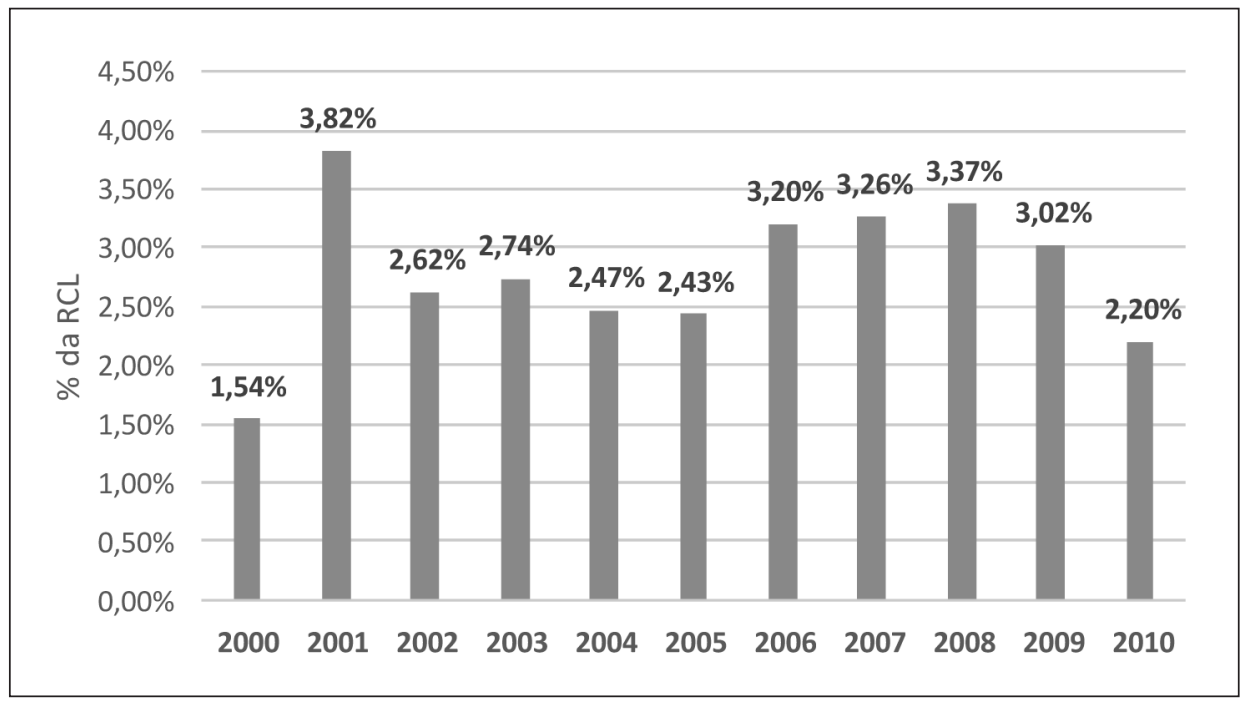

Fonte: Elaborado com base nos dados do Finbra/STN.

\subsection{0 equilíbrio das contas públicas dos municípios alagoanos}

Verificamos ainda se as regras da LRF que estabeleciam limites representaram mecanismos capazes de garantir o equilíbrio fiscal das contas públicas dos municípios alagoanos. Para analisar esse tipo de comportamento, utilizamos o Índice de Resultado Fiscal (IRF), obtido pela relação entre as despesas orçamentárias totais e a receita orçamentária total, subtraindo-se as operações de crédito. ${ }^{16} \mathrm{Um}$ IRF inferior ou igual a 100\% representa uma situação de equilíbrio fiscal e valores superiores a 100\% demonstram a ocorrência de déficits fiscais.

Os resultados apresentados na tabela 6 demonstram que a LRF com seus limites estabelecidos, isoladamente, não representaram instrumentos capazes de garantir o equilíbrio fiscal das contas públicas dos municípios alagoanos, visto que em 63,36\% dos exercícios financeiros analisados surgiram situações orçamentárias deficitárias.

Conforme apresentado anteriormente, as despesas dos municípios alagoanos cresceram em níveis superiores às receitas. Tais resultados apontam que o cumprimento dos limites impostos pela LRF, no tocante às despesas com pessoal e controle do endividamento público, representa uma condição necessária, porém não suficiente, para garantir situações de equilíbrio fiscal.

\footnotetext{
${ }^{16}$ Segundo Oliveira (2009), a utilização dessa metodologia revela os possíveis desequilíbrios existentes nas contas públicas.
} 
Tabela 6

Equilíbrio fiscal dos municípios alagoanos - 2000-10 (\%)

\begin{tabular}{|ccccccc|}
\hline Ano & $\begin{array}{c}\text { Até 5.000 } \\
\text { habitantes }\end{array}$ & $\begin{array}{c}\text { De 5.001 } \\
\text { a 20.000 } \\
\text { habitantes }\end{array}$ & $\begin{array}{r}\text { De 20.001 } \\
\text { a 100.000 } \\
\text { habitantes }\end{array}$ & $\begin{array}{r}\text { De } 100.001 \\
\text { a 500.000 } \\
\text { habitantes }\end{array}$ & $\begin{array}{r}\text { Mais de } \\
500.000 \\
\text { habitantes }\end{array}$ & Total \\
\hline 2000 & 99,64 & 100,02 & 100,94 & 100,06 & 87,94 & 95,99 \\
2001 & 98,94 & 99,54 & 99,40 & 106,22 & 105,42 & 102,12 \\
2002 & 100,94 & 100,04 & 101,32 & 101,75 & 102,31 & 101,44 \\
2003 & 104,37 & 101,51 & 104,43 & 113,37 & 105,47 & 104,99 \\
2004 & 102,23 & 101,01 & 100,06 & 104,39 & 101,59 & 101,13 \\
2005 & 96,14 & 97,89 & 98,75 & 99,08 & 99,56 & 98,85 \\
2006 & 98,50 & 101,21 & 102,42 & 102,88 & 108,13 & 104,08 \\
2007 & 98,92 & 96,51 & 99,38 & 108,15 & 101,38 & 100,23 \\
2008 & 101,11 & 97,11 & 100,14 & 93,12 & 89,14 & 95,24 \\
2009 & 103,64 & 101,83 & 103,46 & 119,36 & 104,55 & 104,82 \\
2010 & 102,18 & 99,79 & 98,60 & 94,32 & 101,53 & 99,49 \\
\hline
\end{tabular}

Fonte: Elaborada com base nos dados do Finbra/STN.

Ainda é possível observar que existe uma relação direta entre as ocorrências de desequilíbrio fiscal e o tamanho dos municípios em termos populacionais. Nota-se que os municípios com população de até 20 mil habitantes apresentaram situações de desequilíbrio em 54,54\% dos exercícios financeiros. Eles aumentaram de acordo com o crescimento do contingente populacional, atingindo 72,72\% nos municípios acima de 100 mil habitantes.

Analisando os resultados de forma individual, percebe-se que no ano de implantação da Lei Complementar no 101/2000, dos 72 municípios analisados, 58,33\% apresentavam desequilíbrios fiscais. Esse resultado atingiu seu limite de 76,39\% em 2003, voltando a cair para uma média de 51,35\% entre 2004-10.

Vale destacar que, durante o período analisado, 90,34\%, em média, dos municípios nessa situação possuíam um estoque populacional entre 20 mil/100 mil habitantes. Os desequilíbrios fiscais verificados necessitam ser analisados com cautela para não serem vistos, de maneira reducionista, como apenas irresponsabilidades dos gestores municipais. Isso porque é preciso considerar que a esfera municipal vem crescentemente assumindo despesas de outras esferas de governo, e esse fato pode ser verificado pelo aumento da participação dos gastos com saúde e educação nas despesas totais dos municípios alagoanos.

Conforme Bremaeker (2012), em 2010 os gastos municipais com ações de outras esferas de governo representaram $4,37 \%$ da receita orçamentária municipal em nível nacional. Nos municípios nordestinos, eles alcançaram 5,02\% dos municípios da região e 7,13\% dos municípios com até 20 mil habitantes. Segundo o autor, nessa faixa populacional tais gastos superam o montante da receita tributária total arrecadada. 
Por sua vez, faz-se necessário ponderar a situação de extrema dependência da maior parte dos municípios alagoanos das receitas intragovernamentais, principalmente as transferências constitucionais. Nos últimos anos, essas fontes de receitas se comportaram de maneira instável ao longo do tempo do ponto de vista de seu volume. Resultado principalmente da política macroeconômica anticíclica adotada pelo governo central para enfrentar a crise financeira internacional estabelecida a partir de 2008. Esses movimentos vêm fragilizando as finanças públicas municipais de maneira constante.

\section{Conclusão}

Criada com o propósito de dificultar desvios e fiscalizar os estados subnacionais, a LRF foi um marco no controle institucional brasileiro e no processo de planejamento governamental. Também trouxe mais instrumentos de controle interno, de eficácia na política fiscal, limites ao endividamento (sobretudo dos estados) e à capacidade de gestores públicos utilizarem-se da máquina pública para fins eleitoreiros. Ademais tornou prioridade institucional as transferências dos pagamentos de encargos de dívidas. Alguns pontos da LRF são considerados ainda deficientes, merecendo ser revistos, como a falta de maior participação popular na definição e fiscalização da aplicação do orçamento público e a perda de autonomia dos entes subnacionais após sua promulgação. Além disso, a nova legislação fiscal não compreende mecanismos de fiscalização da execução orçamentária por parte do governo federal. Por exemplo, as despesas com pessoal e nível de endividamento não possuem regras ou tetos para essa esfera da União.

Os resultados a que chegamos para o caso do estudo dos municípios alagoanos indicam que de forma consolidada os limites com as despesas com pessoal e endividamento foram cumpridos logo de imediato à promulgação da legislação fiscal. Todavia, no longo prazo, os limites estabelecidos são difíceis de serem atingidos, causando quase sempre situações de desequilíbrios nas finanças públicas.

Vale destacar que neste trabalho não pretendemos minimizar a importância dos gastos com pessoal no controle das finanças municipais. Entretanto, os resultados apontam que outros componentes dos gastos também devem ser considerados; é o caso das despesas financeiras, que cresceram consideravelmente no período em análise e ficaram protegidas do rigor da LRF.

De forma consolidada, os municípios do estado de Alagoas cumpriram os limites impostos para gastos com pessoal e encargos; todavia, os resultados sinalizaram que houve um crescimento da relação DP/RCL. Esse cenário decorreu da elevação das despesas com pessoal em níveis superiores ao da RCL, porque essa tem sido sistematicamente afetada negativamente pela redução dos recursos transferidos, em decorrência das políticas macroeconômicas anticíclicas adotadas desde 2008 pelas autoridades econômicas e monetárias do país.

Os dados demonstram, ainda, que o limite universal de 60\% da RCL imposto pela LRF não atinge de forma homogênea todos os municípios alagoanos. A análise por grupo populacional indica que os municípios menos populosos e mais dependentes de transferências in- 
tergovernamentais são os que apresentam maior relação DP/RCL, estando eles também mais sujeitos aos efeitos negativos da política anticíclica adotada.

Quanto ao limite imposto para a relação DCL/RCL, os resultados apresentados indicam que o nível considerado adequado se apresenta bem distante da realidade dos municípios alagoanos. Da amostra analisada, a única cidade que apresentava índices acima do estabelecido pela LRF nos anos de sua promulgação era Maceió. Entretanto, já a partir do ano seguinte ela conseguiu reverter a situação e passou a enquadrar suas finanças públicas às regras adotadas.

O limite estabelecido pela LRF para os gastos com pessoal e encargos não foi suficiente para reduzir a participação desse tipo de despesa no total das despesas públicas dos municípios alagoanos. Conforme foi visto, ocorreu exatamente o contrário, a participação dos gastos com pessoal cresceu de forma significativa no período, superando no ano de 2010 todo o montante das outras despesas correntes. Esse movimento pressionou significativamente para baixo os níveis de investimentos públicos, confirmando uma tendência já verificada em outros estudos dessa natureza de que aquelas despesas acabam prejudicando a capacidade dos municípios em realizar obras importantes ou ampliar a oferta de serviços públicos por meio de investimentos.

Por fim, é preciso mencionar que, para além das metas fiscais que os gestores públicos devem atingir para respeitar as regras estabelecidas pela LRF, deve-se perseguir também metas sociais, tais como: a redução da mortalidade e do trabalho infantil, do índice de analfabetismo, da evasão escolar, das diversas formas de violência urbana etc. Esses índices sinalizam a melhoria da qualidade de vida daqueles que carecem mais amplamente de políticas públicas.

\section{Referências}

BARACHO, Hertha U. Regionalismo e federalismo: as novas feições do Estado brasileiro pós Constituição de 1988. In: ENCONTRO NACIONAL DO CONPEDI, XIX, 2010, Fortaleza.

BERCOVICI, Gilberto. Desigualdades regionais, Estado e Constituição. São Paulo: Max Limonad, 2003.

BOUERI, Rogério et al. A CF/88 e as desigualdades regionais. In: CARDOSO JR., José C. et al. (Org.). Constituição brasileira de 1988 revisitada: recuperação histórica e desafios atuais das políticas públicas nas áreas regional, urbana e ambiental. Brasília: Ipea, 2009. v. 2, p. 61-90.

BRASIL. Lei Complementar 101. Diário Oficial da União, Brasília, 4 maio 2000.

BREMAEKER, François E. J. Despesas municipais com serviços, ações e programas de competência dos estados e da União em 2010. Salvador: Ibam, 2012.

CHIEZA, Rosa A. O ajuste das finanças públicas municipais à Lei de Responsabilidade Fiscal: os municípios do RS. Tese (doutorado) — Universidade Federal do Rio Grande do Sul, Porto Alegre, 2008.

CORBARI, Ely C. Grandes municípios brasileiros: estrutura do endividamento e impactos da Lei de Responsabilidade Fiscal. Dissertação (mestrado) — Universidade Federal do Paraná, Curitiba, 2008. 
FIORAVANTE, Dea G. et al. Lei de responsabilidade fiscal e finanças públicas municipais: impactos sobre despesas com pessoal e endividamento. Brasília: Ipea, 2006. Texto para Discussão n. 1223. Disponível em: <www.ipea.gov.br/portal/images/stories/PDFs/TDs/td_1223.pdf>. Acesso em: 15 jan. 2014.

GERIGK, Wilson; CLEMENTE, Ademir; RIBEIRO, Flávio. O padrão de endividamento público nos municípios brasileiros de porte médio após a Lei de Responsabilidade Fiscal. Revista Ambiente Contábil, v. 6, n. 1, p. 122-140, jan./jun. 2014.

GIUBERTI, Ana C. Efeitos da Lei de Responsabilidade Fiscal sobre os gastos dos municípios brasileiros. Dissertação (mestrado) — Universidade de São Paulo, São Paulo, 2005.

LOPREATO, Francisco C. Caminhos da política fiscal no Brasil. São Paulo: Unesp, 2013.

MENEZES, Rafael T.; TONETO JR., Rudinei. Regras fiscais no Brasil: a influência da LRF sobre as categorias de despesa dos municípios. Planejamento e Políticas Públicas (PPP). Brasília: Ipea, jun./ dez. 2006. (Texto para Discussão n. 29).

NAZARETH, Paula A.; PORTO, Luiz F. L. As finanças dos municípios brasileiros: o caso do Rio de Janeiro. Rio de Janeiro: Cepal, 2002. Disponível em: <www.cepal.org/de/noticias/paginas/0/9200/ 5nazareth.pdf>. Acesso em: 13 mar. 2013.

OLIVEIRA, Fabrício A. de. Crise, reforma e desordem do sistema tributário nacional. São Paulo: Unicamp, 1995.

OLIVEIRA, Fabrício A. de. Economia e política das finanças públicas no Brasil. São Paulo: Hucitec, 2009. REGIS, André. O novo federalismo brasileiro. Rio de Janeiro: Forense, 2008.

RIANI, Flavio. Economia do setor público: uma abordagem introdutória. 4. ed. São Paulo: Atlas, 2009.

Anderson Henrique dos Santos Araújo é mestre em economia aplicada. Professor assistente da Universidade Federal de Alagoas (Campus do Sertão/Ufal). E-mail: anderson.hsa@gmail.com.

José Emilio dos Santos Filho é mestre em economia aplicada. Economista da Universidade Federal de Alagoas (Ufal).E-mail: filho.emilio@gmail.com.

Fábio Guedes Gomes, mestre em economia e doutor em administração pública pela Universidade Federal da Bahia (Ufba). Professor adjunto da Faculdade de Economia, Administração e Contabilidade (Feac) da Universidade Federal de Alagoas (Ufal). Tutor do PET-Economia da FEAC. E-mail: fbgg30@yahoo.com.br. 